\title{
DRY MOUTH SCALE LAUNCHED
}

On 2 September 2011 the Challacombe Scale was launched: an easy-to-use tool for identifying and quantifying the severity of dry mouth. The scale was developed by Professor Stephen Challacombe at King's College London and is suitable for use by general dental practitioners, dental hygienists and dental therapists.

The Challacombe Scale is based on a Clinical Oral Dryness Score (CODS) and lists ten key features of dry mouth, accompanied by example images, and allocates one point for each feature.
The patient's additive score indicates whether the dry mouth is mild (a score of 1-3), moderate (4-6) or severe (7-10) and suggests what action to take next.

Free posters of the scale are available from CCMed, who hosted the launch at Tylney Hall, Hampshire, and practices are encouraged to position them prominently in the waiting room and include patients' scores in their clinical notes.

For further information and to receive a free Challacombe Scale poster for your practice you can visit www. challacombescale.co.uk.

\section{APPLICATIONS FOR GRANTS AND FELLOWSHIPS INVITED}

The Faculty of Dental Surgery of The Royal College of Surgeons of England is inviting applications for the 2012 Research Grant and Fellowship competitions. This includes the Small Grants Scheme; the FDS Research Fellowship in any aspect of specialist dentistry and oral and maxillofacial surgery; the joint FDS-Wellcome Trust clinical research training Fellowships; and the King's College London John McLean Fellowship in applied and basic science-based biomaterials research in dentistry.

The closing date for all applications is 27 January 2012 at 5pm. Further details and application forms can be found at www.rcseng.ac.uk/fds/ grants-awards-and-fellowships.

\section{DIARY}

\section{NOVEMBER}

The Pan Dental Society Meeting
Date: 11-12 November 2011
Location: Liverpool
www.pandental.co.uk
BACD 'Something to Smile About'
conference
Date: $11-12$ November 2011
Location: Hilton London Metropole Hotel
Email: suzy@bacd.com
ADI UK Members' National Forum
Date: $11-12$ November 2011
Venue: King's College London
Tel: 020 8487 5555
www.adi.org.uk/forum11
$\mathbf{2 0 1 2}$

Jamaica Dental Association 48th National Convention Date: 15-15 February 2012 Venue: Iberostar Hotels \& Resorts www.jamaicadentalassociation.org
Dental Hypnosis 1: Technical

Foundations and Dental Hypnosis 2: Applied Clinical Skills

Date: 22-23 February 2012

Location: Central London

Telephone: 02073851166

Email: info@ihmdp.org

BDA Events: Setting up in practice: how to succeed in challenging times Date: 9 March 2012

Location: Leeds

Telephone: 02075634590

(quote 'SUIP1'to book a second place half price)

Excellence in Dentistry 2012 Conference Date: 26-29 April 2012

Location: Istanbul www.excellence-in-dentistry.org

Dental Sedation Teachers Group Annual Symposium 2012

Date: 22 May 2012

Venue: St. Paul's Mecure Hotel, Sheffield Email: sheelah.harrison@sheffield.ac.uk www.dstg.co.uk 